\title{
Serological diagnosis of myasthenia gravis and its clinical significance
}

\author{
Yi Li, Yuyao Peng, Huan Yang \\ Department of Neurology, Xiangya Hospital, Central South University, Changsha, China \\ Contributions: (I) Conception and design: H Yang; (II) Administrative support: None; (III) Provision of study materials or patients: Y Li, Y Peng; (IV) \\ Collection and assembly of data: Y Li, Y Peng; (V) Data analysis and interpretation: All authors; (VI) Manuscript writing: All authors; (VII) Final \\ approval of manuscript: All authors. \\ Correspondence to: Yang Huan, MD. Department of Neurology, Xiangya Hospital, Central South University, 87 Xiangya Road, Changsha 410000 , \\ China. Email: yangh69@126.com.
}

\begin{abstract}
Myasthenia gravis (MG) is the most common immune-mediated disorder of the neuromuscular junction. Anti-acetylcholine receptor (anti-AChR), anti-muscle-specific kinase (anti-MuSK), and antilipoprotein receptor-related protein 4 (anti-LRP4) antibodies are the three well-defined pathogenic antibodies. Patients with MG can also have other antibodies, such as anti-titin, anti-ryanodine receptor (anti-RyR), anti-Agrin and anti-KV1.4 antibodies. Since MG is heterogeneous in terms of pathophysiology, antibody status, and other factors, serological tests are crucial for clinical diagnosis confirmation and treatment choice. Herein, we review the different methods for detection of various antibodies involved in MG and their sensitivity and specificity. The understanding of these elements should be useful for improving the diagnosis and determining how to adapt the existing therapies to the requirements of each patient.
\end{abstract}

Keywords: Myasthenia gravis (MG); antibodies; radioimmunoprecipitation assay (RIPA); enzyme-linked immunosorbent assay (ELISA); cell-based assay (CBA)

Submitted Jan 31, 2019. Accepted for publication Jul 09, 2019. Published online Sep 29, 2019.

doi: $10.21037 /$ atm-19-363

View this article at: https://dx.doi.org/10.21037/atm-19-363

\section{Background}

Myasthenia gravis (MG) is an autoimmune disorder caused by antibodies targeting the neuromuscular junction, which has a reported worldwide prevalence of $40-180$ per million people, and an annual incidence of 4-12 per million people (1-4). The antibodies attack and destroy the postsynaptic structures or disturb the Agrin/lipoprotein receptor-related protein 4 (LRP4)/muscle-specific tyrosine kinase (MuSK)/ Dok7/rapsyn pathway. These processes lead to an impaired neuromuscular junction transduction characterized by fluctuating muscle weakness and fatigability $(5,6)$. The muscle weakness can be generalized or localized. The respiratory muscles are less affected; however, their involvement can be life-threatening.

The following antibodies have been reported in MG: anti-acetylcholine receptor (anti-AChR), anti-musclespecific tyrosine kinase (anti-MuSK), anti-lipoprotein receptor-related protein 4 (anti-LRP4), anti-agrin, antititin, anti-ryanodine receptor (anti-RyR), anti-collagen Q, and anti-voltage-gated potassium channel (anti-KV1.4) antibodies (Figure 1). MG is a heterogeneous disease in terms of pathophysiology, depending on the antibody status and other factors (Table 1). Serological tests are important in the management of patients with this disease because of their potential implications: (I) autoantibodies against the postsynaptic membrane are the most important biomarkers for the diagnosis of $\mathrm{MG}$ as they are widely available and antibody detection is important for distinguishing congenital myasthenia from MG; (II) patients with $M G$ can be stratified into several subgroups: anti-AChR-positive MG (including early-onset and late- 


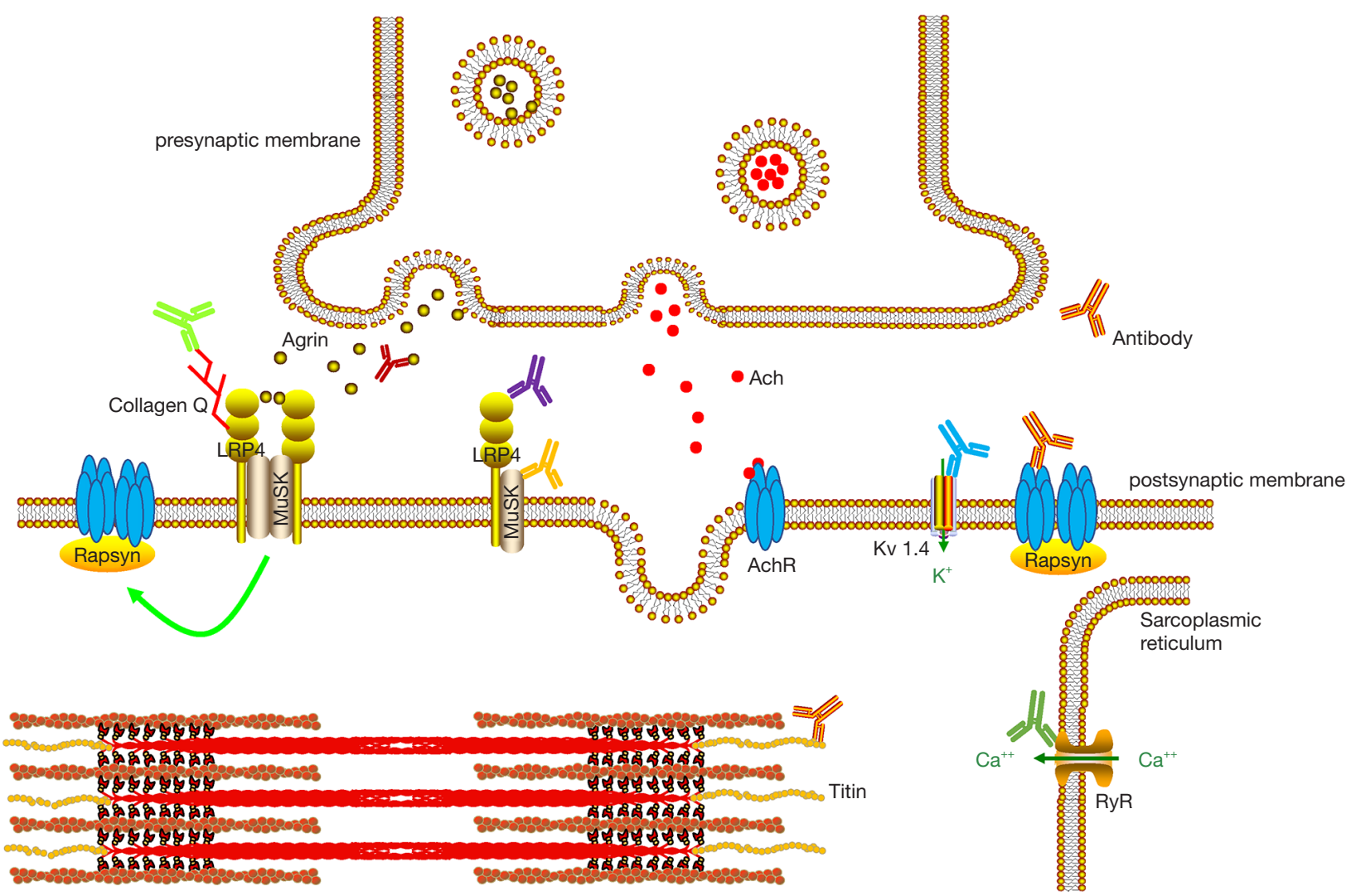

Figure 1 The reported antibodies in MG and position of their antigens. LRP4, lipoprotein receptor-related protein 4; MuSK, musclespecific tyrosine kinase; AChR, acetylcholine receptor; RyR, ryanodine receptor; MG, myasthenia gravis.

onset), anti-MuSK-positive MG, anti-LRP4-positive MG, seronegative $\mathrm{MG}$, thymoma-associated $\mathrm{MG}$, and ocular MG. The antibody status is an important basis for MG classification; (III) the treatment regimen for MG varies according to the different antibodies. For example, patients with an anti-MuSK-positive MG have a poor response to oral acetylcholinesterase inhibitors. In fact, these medications may even be deleterious in these patients. 3,4-diaminopyridine is suggested as a potential substitute in these cases (7-9). Plasma exchange is usually the preferred over intravenous immunoglobulin treatment in patients with deteriorating anti-MuSK-positive MG; (IV) because the level of antibodies decreased in most patients with MG after plasma exchange or immunosuppressants therapy, the antibody levels might be useful as a monitoring indicator for therapy (10-12), although the antibody level has a limited value in monitoring of the disease due to the heterogeneity of the antibodies; (V) the antibody status is one of the factors influencing the outcome in patients with MG (13). Patients with ocular MG with anti-AChR or anti-MuSK antibodies were prone to develop generalized MG $(14,15)$, whereas doublenegative patients, those without anti-AChR or anti-MuSK antibodies, had a better prognosis (13). In summary, serological testing is crucial for diagnosis confirmation and therapy decision in patients with MG and is therefore recommended in the management of these patients.

\section{Anti-AChR antibodies}

Anti-AChR antibodies are the most common and highly specific antibodies in MG, found in $70-85 \%$ of all patients with MG $(5,6,16,17)$, in $85-90 \%$ of patients with generalized $M G$, and in only $50-60 \%$ of patients with ocular MG (18-22). In the Chinese population, anti-AChR antibodies were present in $50-91.2 \%$ of patients with 
Table 1 Clinical characters in different antibodies status

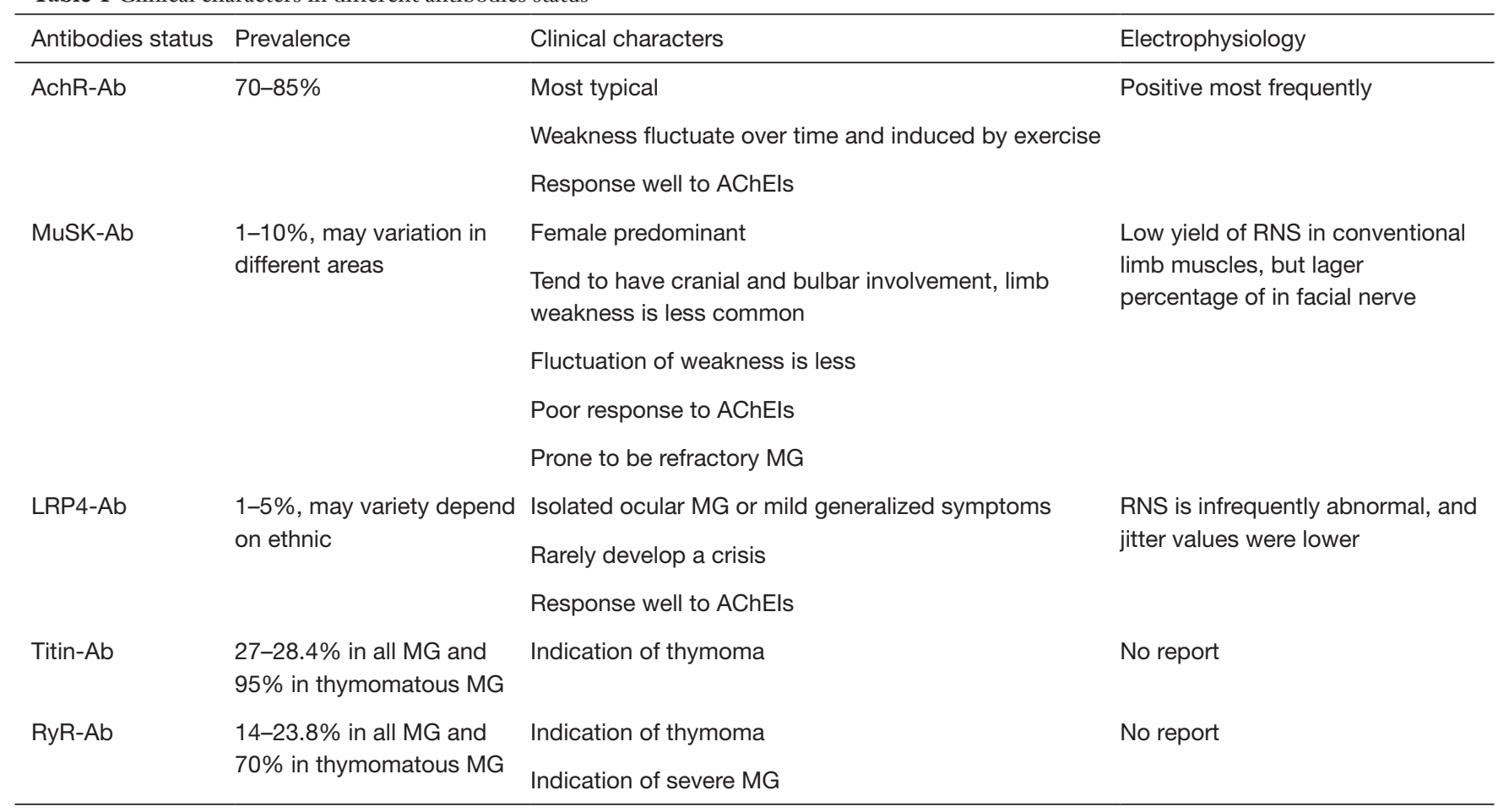

Ab, antibody; AChR, acetylcholine receptor; MuSK, muscle-specific kinase; LRP4, lipoprotein receptor-related protein 4; RyR, ryanodine receptor; MG, myasthenia gravis; AChEls, acetylcholinesterase inhibitions; RNS, repetitive nerve stimulation.

ocular MG, in $82.4-86.4 \%$ of patients with generalized MG, and in 72-86.2\% of all patients with MG (23-26). These results are similar to the reported prevalence of anti-AChR antibodies worldwide, even though one group reported a higher prevalence $(91.2 \%)$ of these antibodies in patients with ocular MG (23). This variation may be due to the difference in the assays and the enrolled population. The pathogenicity of the anti-AChR antibodies has been well understood. These antibodies disturb the transmission in the neuromuscular junction primarily by complement binding and activation, leading to damage of the post synaptic membrane, by crosslinking to the AChRs, leading to accelerated endocytosis and degradation of these receptors, and direct blockade of the AChR binding sites also involved (27-31). Anti-AChR antibodies mostly belong to the IgG1 and IgG3 subtypes and primarily target the main immunogenic region (32). The antibodies against the $\alpha$ subunit of the AChRs are more pathogenic than those against the $\beta$ subunit (33). In most studies, there was no correlation between the antiAChR antibody concentration and the disease severity among different individuals $(5,6,16,17)$. However, these studies focused on the total anti-AChR antibody level. Considering that the epitope variability influences the disease severity (33), identifying the binding region and subclass of antibodies may improve the correlation. The levels of antibodies against the main immunogenic region had a stronger correlation with the disease severity than those of the total anti-AChR antibodies (34). The value of repeated anti-AChR antibody testing in patients with MG is controversial. It may be useful for evaluation of the short-term therapy effect, particularly after plasma exchange. A correlation has also been noted between the changes in the anti-AChR antibody concentration and the disease severity. A strong correlation existed between the change in anti-AChR antibody concentration and the change in the clinical condition during immunosuppressive treatment and after thymectomy, whereas only a weaker correlation was present in periods without immunosuppression (35). In another report, there was a longitudinal association between the concentration of anti-AChR antibodies and the Myasthenia Gravis 


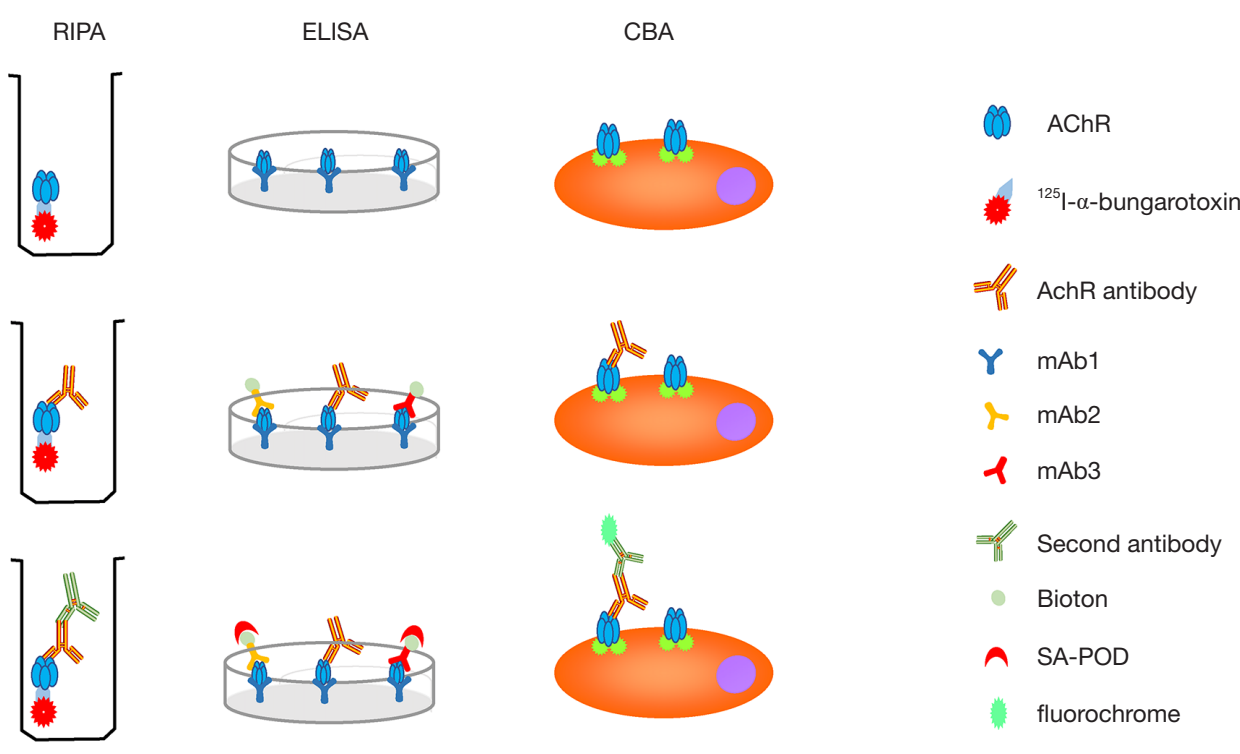

Figure 2 Three techniques employed to detect anti-AChR antibodies in serum of MG patients: RIPA, ELISA and the CBA. RIPA, radioimmunoprecipitation assay; ELISA, enzyme-linked immunosorbent assay; CBA, cell-based assay; AChR, acetylcholine receptor; SAPOD, streptavidin-peroxidase; MG, myasthenia gravis.

Foundation of America (MGFA) classification in the subgroup with immunosuppressive treatment (36). These two studies adopted the MGFA classification to evaluate disease severity. Recently, the MG severity score was also used for assessment of the clinal condition. No significant correlation was demonstrated between the absolute change in the anti-AchR antibody titers and any severity measure; however, there was a strong correlation between the percentage change in the antibody level and the change in the manual muscle testing grade $(12,37)$.

\section{Radioimmunoprecipitation assay (RIPA)}

RIPA is the most rigorously validated test for anti-AChR antibody detection. It was first applied to detect antiAChR antibodies in 1976 (20). First, the AChRs are labeled with ${ }^{125} \mathrm{I}$ - $\alpha$-bungarotoxin, which has a high affinity for the nicotinic AChRs. After incubation with the serum to be tested, a second antibody is added to precipitate the ${ }^{125} \mathrm{I}-\alpha$ bungarotoxin-anti-AChR complex. Washing steps should be performed to prevent a high background after the AChR labelling and incubation steps. The precipitate is counted and the precipitation rate is compared to that of healthy control samples (Figure 2). The AChRs were initially obtained from human amputated limb muscle until Sine et al. developed a new way to produce functional human AChRs from the TE671 cell line in 1988 (38). However, the AChRs derived from TE671 cells cannot replace the human muscle AChRs because the overall sensitivity was 7\% less when using TE671 cell-derived AChRs (39). This is due to the fact that there are two subtypes of human muscle AChRs: fetal $(2 \alpha \beta \gamma \delta)$ and adult $(2 \alpha \beta \varepsilon \delta)$. The TE671 cells mainly express the fetal subtype. However, in some patients with ocular symptoms or low anti-AChR antibody titers, the antibodies mainly target the adult AChR subtype. To solve this problem, further improvement was made in 1996 by stably transfecting TE671 cells with cDNA encoding $\varepsilon$ subunit (TE671- $\varepsilon$ ) to produce a high concentration of adult AChRs $(40,41)$. At present, RIPA for serum antiAChR antibodies is mainly based on ${ }^{125} \mathrm{I}$ - $\alpha$-bungarotoxinlabelled AChRs, which are mixed, containing both fetal and adult form subtypes. A carefully balanced mixture of detergent-solubilized fetal and adult forms of the receptor is the optimum. Currently, the overall diagnostic sensitivity of the routine RIPA to detect anti-AChR antibodies is $82 \%$ (42), and its specificity is very high, up to $98 \%$. Because of its high sensitivity and specificity as well as widespread use, RIPA is considered as the "golden standard" for anti-AChR antibody testing. In addition, titres can be accurately determined with this method and 
the assay can be performed quickly, in 1-2 days. There are commercially available testing kits, such as RiaRSR ${ }^{\mathrm{TM}}$ AChRAb from RSR limited (United Kingdom), ARAb RIA from IBL international (Germany), AChRAb RIA from Diasource (Belgium). The main disadvantage of RIPA is its radioactivity.

\section{Enzyme-linked immunosorbent assay (ELISA)}

ELISA for anti-AChR antibodies was first performed by Furukawa et al. (43). The ${ }^{125} \mathrm{I}-\alpha$-bungarotoxin was replaced by HRP-linked $\alpha$-bungarotoxin and the results were similar to those obtained using RIPA. However, this method was not widely adopted. Hewer $e t$ al. developed the competitive ELISA (44). The mAb1 antibodies, a type of monoclonal antibodies against AChRs (mixture of fetal and adult), were used to coat the ELISA plate wells, and the other two types, $\mathrm{mAb} 2$ and $\mathrm{mAb} 3$, were labeled with biotin. In the presence of anti-AChR antibodies, a sandwich is formed between the coated MAb1 antibodies, the anti-AChR antibodies, and the biotin-labeled mAb2 and $\mathrm{mAb} 3$ antibodies. When anti-AChR antibodies from the test serum are included, the formation of this sandwich is inhibited and the amount of biotinylated $\mathrm{mAb}$ antibodies bound to the plate wells (via AChRs and immobilized $\mathrm{mAb}$ antibodies) is reduced. The higher the concentration of anti-AChR antibodies in the test serum, the greater the inhibition of the mAb-biotin binding [detected by the addition of streptavidin-peroxidase (SA-POD)], thus providing a quantitative anti-AChR antibody ELISA (Figure 2). There was a good agreement between RIPA and ELISA for the anti-AChR antibody measurement $(\mathrm{r}=0.85 ; \mathrm{n}=83 ; \mathrm{P}<0.001)$. This method has a sensitivity and a specificity at least as high as those of RIPA. ELISA is a non-radioactive assay, and as it has a similar performance to that of RIPA, it can be a good alternative for laboratories where radioactive assays cannot be performed. There are commercially available inhibition ELISA kits, such as that by RSR (United Kingdom).

\section{Cell-based assay (CBA)}

The CBA for anti-AChR antibodies was developed in $2008(45,46)$. Cultured human embryonic kidney (HEK) cells were transfected with the AChR subunit and rapsyn cDNAs. Rapsyn, which is a key component of the subsynaptic cytoskeletal complex, was added in order to obtain dense clusters of AChRs on the membrane of HEK cells. When a test serum is added, the antibodies bind to the clustered AChRs on the cell membrane. Subsequently, second, fluorescence-labeled antibodies are added to detect the cell membrane-bound anti-AChR antibodies and the results can be analyzed by flow cytometry (Figure 2). CBA has a higher sensitivity than RIPA and a specificity of nearly $100 \%$ (47). It detected low-affinity anti-AChR antibodies in $38.1-66 \%$ of patients with MG who were previously regarded as being negative on RIPA (45-47). In addition, $50 \%$ of the previously seronegative (antiAChR-negative) patients with ocular MG were found to be anti-AChR-positive when tested with CBA (45). The low-affinity anti-AChR antibodies were all of the IgG1 subtype and pathogenic in an animal model, indicating their similar mechanisms. CBA is a non-radioactive assay with a higher sensitivity and specificity. Furthermore, the antigens are expressed in a clustering form on a cell surface, which is more similar to the antigens in vivo; hence, it is more a sensitive method than the RIPA and ELISA assays with purified AChR molecules. CBA can offer a semi-quantitative estimation of autoantibody titers and quantification can be easily performed with flow cytometry. However, it is more laborious and there is no commercial kit available at present.

\section{Other assays}

Fluorescence immunoprecipitation assays (IFPA) was developed in Oxford, UK, and Yang et al. applied it in Chinese patients for anti-AChR antibody detection (48). Transfected HEK 293 cells were used to produce fetal and adult AChRs tagged with fluorescent proteins [enhanced green fluorescence protein (EGFP)]. The AChR-EGFP are mixed with serum from patients and then protein A sepharose beads are added to catch the antibody-receptor complexes. After rotation and washing, the beads are transferred to conical bottom plates and the fluorescence units values are read using a fluorescent plate reader to estimate the titers of anti-AChR antibodies. IFPA has a good agreement with RIPA $\left(r^{2}=0.6 ; \mathrm{P}<0.0001\right)$. Although, IFPA was found not to be as sensitive as RIPA $(76 \% v s$. $80 \%$, respectively), it may be due to the relatively small sample size. The advantage of this approach is that it can use different fluorescence-tagged proteins (such as mixed with MuSK-mcherry) for detection of antibodies against different antigens in the same sample. 


\section{Anti-MuSK antibodies}

Anti-MuSK antibodies were first described in antiAChR-negative patients with MG in 2001 (49,50). They can be detected in $1-10 \%$ of all patients with $M G$ and in $13-41 \%$ of anti-AChR-negative patients $(51,52)$. This variety depends on the geographical location (5355). Among the Chinese population, it was found in $4 \%$ of anti-AChR-negative patients with $M G$ and in $2.3-5.9 \%$ of all patients with MG $(24,25,48)$. Anti-MuSK antibodies are predominantly IgG4 antibodies that do not bind complement. Hence, they were once considered to be "benign antibodies" or bystanders. Klooster et al. proved the pathogenicity of these antibodies in mice and observed a reduced density and a fragmented area in the neuromuscular junction AChRs (56). Huijbers et al. and Koneczny et al. elucidated the underlying pathogenic mechanism. Anti-MuSK-IgG target a structural epitope in the first Ig-like domain of MuSK, preventing the binding between MuSK and Lrp4, thereby inhibiting the agrin-induced clustering $(57,58)$. In summary, antiMuSK antibodies disturb the AChR cluster formation and aggregation on the postsynaptic membrane rather than decreasing or blocking AChRs (16,59). In contrast to the anti-AChR antibodies, both in individual cases and in the whole population, a correlation was found between the levels of antibodies and the disease severity (60). The correlation may be because, unlike heterogeneity of AChR-Abs, the majority of MuSK-Abs targets the first Ig like domain. Patients with anti-MuSK antibodies were prone to have refractory $M G$ and were more likely to develop respiratory weakness $(50,61)$. Their response to acetylcholinesterase inhibitors is often insufficient or their condition may even exacerbate after administration of pyridostigmine. Furthermore, these patients respond better to plasma exchange than to intravenous immunoglobulin treatment (61).

\section{RIPA}

RIPA is regarded as a standard test for anti-MuSK antibodies as well. The procedure is similar to that of RIPA for anti-AChR antibodies. Antigens labeled with ${ }^{125} \mathrm{I}$ were derived from engineered HEK 293 cells expressing human MuSK ectodomain or recombinant rat MuSK $(51,62)$. The ${ }^{125} \mathrm{I}-\mathrm{MuSK}$ is used to precipitate the anti-MuSK antibodies. Using this method, $13-41 \%$ of anti-AChR-seronegative patients were found to be anti-MuSK-positive. Its specificity is speculated to range from $97 \%$ to $100 \%$. Commercial RIPA kits are available, including that by RSR (United Kingdom) and CISbio (France). Moreover, Trakas et al. developed a two-step RIPA, using immobilized antigens to enrich the antibodies before the routine RIPA (63). This two-step RIPA has a higher sensitivity, but there is no available commercial kit.

\section{ELISA}

ELISA was the first reported anti-MuSK-antibody assay (49). Antigens were derived from MuSK-transfected COS7 cells and were coated on the plate. Plasmas from patients are added. The bound antibodies are detected by horseradish peroxidase (HRP), followed by substrate and measuring by absorbance. ELISA is a substitute for RIPA for anti-MuSK antibodies detection (64). A commercial ELISA kit can be acquired from IBL international (German). Their measurements of MuSK autoantibodies showed that in 253 serum samples sensitivity of ELISA is up to $95.8 \%$ and specificity is $100 \%$ compare to RIPA (https://www.ibl-international.com/en/musk-ab-elisa).

\section{$C B A$}

CBA was also applied in the diagnosis of MG with antiMuSK antibodies. HEK 293 cells transfected with fulllength human MuSK cDNA were used for anti-MuSK antibody detection $(46,65)$. CBA is more sensitive than RIPA or ELISA, and its specificity is estimated to be 97-98\% $(46,65,66)$. Furthermore, the CBA-detected anti-MuSK-IgGs were capable of disrupting the agrininduced AChR clustering in myotube cultures $(46,65)$. No commercial kit is available at present.

\section{Other assays}

IFPA was used for anti-MuSK antibody measurement in China by Yang et al. $(24,25,48)$. The extracellular domain of human MuSK, covalently tagged with mcherry, was expressed and secreted by stably transfected insect cell line S2 and then purified through affinity column. The purified MuSK-mcherry were mixed with AChR-EGFP and used to measure both antibodies in the same assay. For anti-MuSk antibody detection, IFPA seems to be in agreement with RIPA, but less sensitive than CBA (two 
patients were positive for anti-MuSK antibodies by both RIPA and FIPA, but CBA was identifying in additional three patients).

\section{Anti-LRP4 antibodies}

Anti-LRP4 antibodies were first found in patients with MG in 2011 (67-69). They can be found in 1-5\% of all patients with MG or $7-32.7 \%$ of the "serum double negative" patients (70). The variation may be due to ethnic differences (70). Two groups have investigated anti-LRP4 antibodies in the Chinese population. Li et al. reported that 2 of all $116(1.7 \%)$ patients with MG and 2 of 50 (4\%) double-seronegative patients were positive for antiLRP4 antibodies (71). Hong et al. found that $7 \%$ of the double-seronegative patients with MG were anti-LRP4positive (25). The prevalence of anti-LRP4 antibodies in China is similar to that Japan, but less than that in Poland $(67,70)$. These antibodies can co-exist with antiAChR or anti-MuSK antibodies and can be detected in other neuroimmune diseases (neuromyelitis optica and multiple sclerosis) $(69,70)$. Anti-LRP4 antibodies were also found in $14.9-23.1 \%$ of patients with amyotrophic lateral sclerosis (ALS). One possible explanation is that the antibodies are generated owing to immune dysfunction in some patients with ALS (72). LRP4 forms a multiprotein complex with MuSK, participating synapse formation and AChR clustering via the agrin/LRP4/MuSK/Dok7/rapsyn pathway $(16,73)$. Anti-LRP4 antibodies block the agrinLRP4 interaction, disturbing the AChR clustering in the membrane. The pathogenicity of anti-LRP4 antibodies has been proved in an animal model (74). Anti-LRP4 antibodies are predominantly of the IgG1 and IgG2 subtypes $(70,75)$. In contrast to patients with anti-MuSK antibodies, most of these patients present with isolated ocular or only mild generalized MG and rarely experience crisis $(67,68,76)$. Thus, in most reports anti-LRP4 antibodies seem to be indicating a more favorable prognosis. However, Higuchi et al. found that a severe limb muscle weakness or a progressive bulbar palsy or both appeared in anti-LRP4positive patients with MG (67). The fact that some of those patients were anti-MuSK-positive may partly explain this difference.

\section{ELISA}

Zhang et al. reported anti-LRP4 antibodies detection through ELISA (69). Briefly, immuno-plates were coated with purified recombinant LRP4, which was derived from HEK293 cells transfected with plasmid encoding full-length ecto-LRP4. The serum to be tested is added, followed by alkaline phosphatase-goat anti-human Ig secondary antibody. The activity of the immobilized alkaline phosphatase is measured to estimate the level of antiLRP4 antibodies. This method found that $9.2 \%$ of doubleseronegative patients with MG were anti-LRP4-positive. Its specificity is estimated to $98 \%$. No commercial ELISA kit is available.

\section{$C B A$}

CBA was developed for anti-LRP4 antibodies to analyze the epidemiology and clinical characteristics of anti-LRP4positive MG (70). HEK293 cells transfected with LRP4GFP-loaded plasmid are used to bind the anti-LRP4 antibodies. Subsequently, fluorochrome-conjugated antihuman IgG antibodies are added to estimate the level of anti-LRP4 antibodies semi-quantitatively. CBA is more sensitive than ELISA, and its specificity is near $98 \%$. No commercial tests for anti-LRP4 antibodies are available.

\section{Anti-titin antibodies and anti-RyR antibodies}

Anti-titin and anti-RyR are antibodies against components of the skeletal muscular cells. As their antigens are intracellular molecules, it is controversial whether they have pathogenic significance in vivo. There was evidence that they can penetrate the cell membrane and bind to their target (77). They might be disease markers rather than mediators of muscle weakness (78) and present in $27-28.4 \%$ and $14-23.8 \%$ MG patients $(24,79)$. Presently, anti-titin-antibody RIPA is a useful tool for serological diagnosis of serum triple-negative patients with MG (namely anti-AChR, anti-MuSK, and anti-LRP4 antibodies are all negative) (80). Of all triple-negative patients, $13.4 \%$ were also anti-titin antibody positive, $3.6 \%$ of patients with other neurological disease were positive, and none of the healthy controls or patients with myopathy. In addition, anti-titin and anti-RyR antibodies have a close relationship with thymoma; antititin antibodies appeared in $95 \%$ of patients with MG with thymoma and anti-RyR antibodies appeared in $70 \%$ of patients with MG with thymoma $(79,81)$. The combination of anti-titin and anti-RyR antibody testing has a $95 \%$ 
sensitivity and a $70 \%$ positive predictive value (79). The presence of these antibodies also indicates severe MG $(79,82)$. In a few patients with MG, autoimmune-mediated myopathies developed, particularly in thymoma-associated MG. These patients with myopathies have autoantibodies against the molecules on skeletal muscles, including Titin$\mathrm{Ab}$ and RyR-Ab. The mechanisms for the development of MG myopathy remain unclear, but it may predict a poor outcome $(83,84)$.

Anti-titin and anti-RyR antibodies were detected by radioimmunoassay or ELISA or RIPA $(24,25,85,86)$. In the Chinese population, these antibodies were found in $64 \%$ and $55 \%$ patients with MG, respectively, and they were present with a high frequency in MG with thymoma (24-26).

\section{Other antibodies}

Anti-agrin antibodies were reported in 2014 (87). Agrin regulates the formation and maintenance of the neuromuscular junction via the agrin/LRP4/MuSK/rapsyn pathway $(16,73,88)$. Anti-agrin antibodies interfere with the function of agrin, leading to a neuromuscular junction impairment. Whether anti-agrin antibodies contribute to the muscle weakness is unclear. They can be detected only in a minority of patients with MG and are accompanied with other antibodies (such as AChR-Ab, MuSK-Ab) $(87,89)$. Antibodies against collagen $\mathrm{Q}$ were detected in $3 \%$ patients with MG but have also been found in healthy controls $(52,90)$. Their diagnostic or pathogenic value remains to be proven. Antibodies against KV1.4 channel are found in $10-20 \%$ of patients with MG. MG with KV1.4-Ab seemed to be of greater severity or with heart impairment $(91,92)$. Thymoma diagnosed by imaging tests was more frequent in the anti-KV1.4-Ab positive patients than in the negative patients and expression of KV1.4 mRNA was found in the abnormal thymus tissue from patients with MG (93).

\section{Clinical application of serological assay}

The performance of serological tests in screened populations and the selection of reasonable methods are important for an accurate diagnosis. We would like to propose the following. First, serological tests should be performed in patients with clinically suspected MG. It means that before the serological test, a clinical evaluation should be performed. Screening of large unselected populations may decrease the positive predictive value of the diagnostic tests. Furthermore, a minority of patients with MG are still seronegative. Their diagnosis could not depend solely on a serological test. In addition, some of these markers can be found in other diseases (such as LRP4-Ab in neuromyelitis optica, multiple sclerosis and ALS). Thus, it is the combination of a positive serological test (including AChR-Ab, MuSK-Ab, LRP4-Ab) and highly suspicious clinical manifestations that establish the MG diagnosis. Second, the proper markers should be selected according to the practical condition. Nine antibodies associated with MG have been reported and new antibodies may be discovered in the future. The detection of all kinds of antibodies for every patient with MG is expensive and unnecessary. Anti-AChR, antiMuSK, and anti-LRP4 antibodies are the most important markers since they are the most common pathogenic antibodies and are not only an important clue for diagnosis but are also the basis for clinical classification and further guide therapy decisions. Not every patient needs to undergo all three antibody tests, because MuSK$\mathrm{Ab}$ and $\mathrm{AChR}-\mathrm{Ab}$ rarely appear in the same patient. We recommend that suspected patients undergo AChR-Ab detection as a first serologic test. MuSK-Ab detection should be performed when AChR-Ab is negative or the patient is highly suspected to have MuSK-associated MG. If the patient is double-negative, the clinical assessment should be reviewed. One should also consider to test other antibodies such as LRP4-Ab, and perhaps also Titin-Ab and Agrin-Ab if. The procedures are displayed in Figure 3. RIPA, ELISA, CBA are popular methods for serological diagnosis of MG and each method has distinct characteristics (Table 2). The RIPA is still the routine assay, with advantages on specificity, sensitivity and reliability. ELISA could be a good alternative to RIPA for institutions that do not perform RIPA. CBA is more sensitive but it is laborious and is not widely adopted. CBA is suitable to detect antibodies in the samples from patients highly suspected by the neurologist but RIPA are negative. CBA also can be used for detection of LRP4.

\section{Conclusions}

Antibody tests are even more important than before in the diagnosis of MG because of the development of assays with a higher sensitivity and the identification of novel antigens in MG. Furthermore, treatment decisions for MG should be personalized; accurate MG subgrouping based on the antibody status is an important step. 


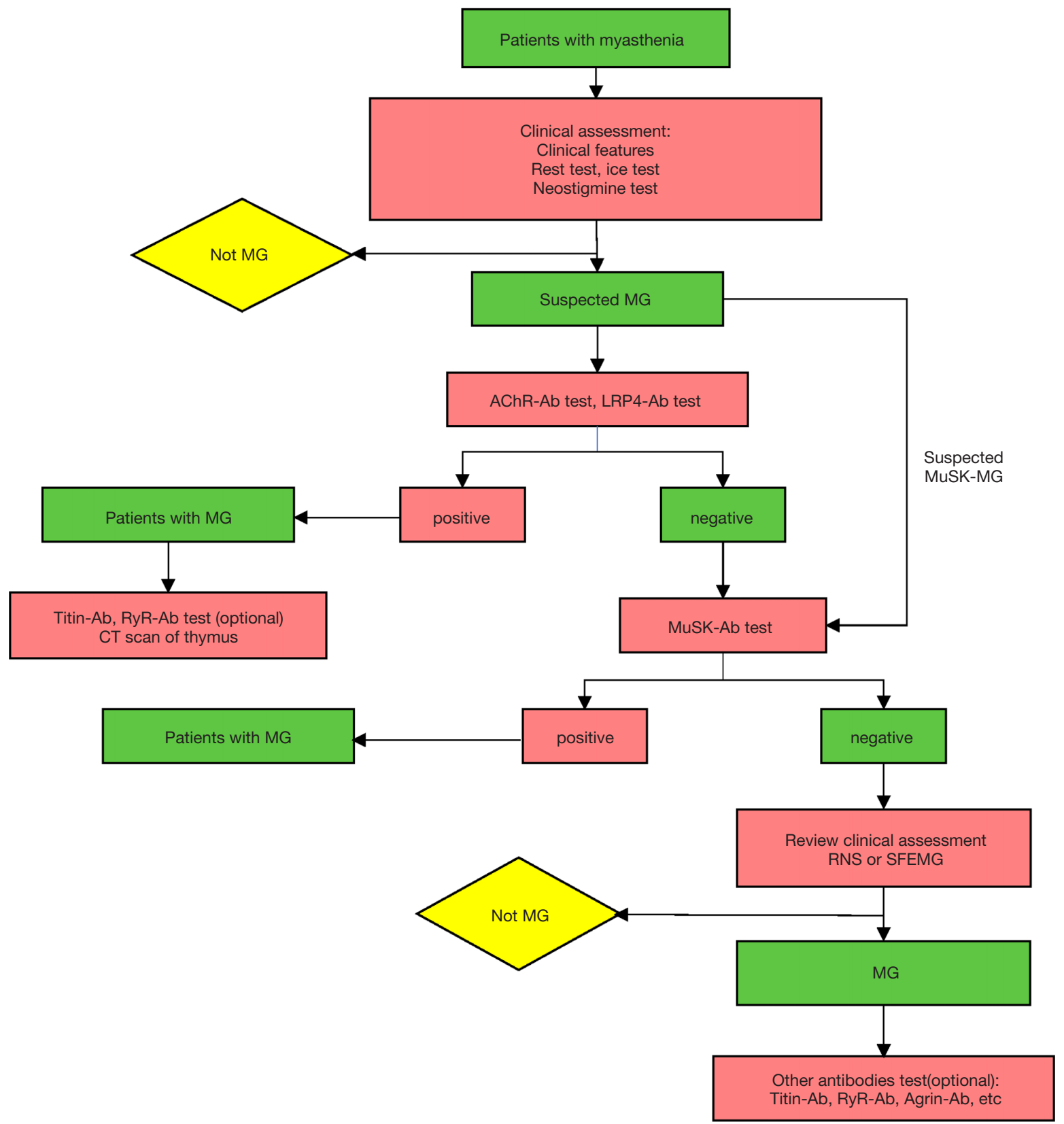

Figure 3 The procedures for detecting MG associated antibodies. Suspicious patients accepting AChR-Ab and LRP4-Ab detection at first serologic test as AChR-Ab is the most common type while LRP4-Ab may co-exist with AChR-Ab or MuSK-Ab. MuSK-Ab detection should be performed when AChR-Ab is negative or the patient is highly suspected to be MuSK-associated MG. If the patient is triple-negative, the clinical assessment should be reviewed and consider to test other antibodies. MG, myasthenia gravis; Ab, antibody; MuSK, musclespecific kinase; AChR, acetylcholine receptor; LRP4, lipoprotein receptor-related protein 4; RyR, ryanodine receptor; RNS, repetitive nerve stimulation; SFEMG, single-fiber electromyography. 
Table 2 Methods for measuring MG associated antibodies

\begin{tabular}{llll}
\hline & RIPA & ELISA & CBA \\
\hline Advantages & "Golden method" & Non-radioactivity & Non-radioactivity \\
& High sensitivity and high specificity & $\begin{array}{l}\text { good alternative to RIPA for institution could not } \\
\text { perform RIPA }\end{array}$ & More sensitive than RIPA \\
& Adopted extensively & Estimate accurate level of antibodies & Better mimic of antigen \\
& expressed in vivo & & Laborious \\
& Commercial kit available & & Commercial kit available
\end{tabular}

RIPA, radioimmunoprecipitation assay; ELISA, enzyme-linked immunosorbent assay; CBA, cell-based assay; MG, myasthenia gravis.

\section{Acknowledgments}

Professor Hai-Feng Li inspired us in this work. Department of Neurology, Xiangya Hospital provided general support. Funding: None.

\section{Footnote}

Provenance and Peer Review: This article was commissioned by the Guest Editors (Hai-Feng Li and Xiangjun Chen) for the series "Laboratory Investigations in Neuroimmunological Diseases and Their Clinical Significance" published in Annals of Translational Medicine. The article has undergone external peer review.

Conflicts of Interest: All authors have completed the ICMJE uniform disclosure form (available at https://atm.amegroups. com/article/view/10.21037/atm-19-363/coif). The series "Laboratory Investigations in Neuroimmunological Diseases and Their Clinical Significance" was commissioned by the editorial office without any funding or sponsorship. YL reports grants from National Natural Science Foundation of China, during the conduct of the study. YP reports grants from National Natural Science Foundation of China, during the conduct of the study. HY reports grants from National Natural Science Foundation of China, during the conduct of the study. The authors have no other conflicts of interest to declare.

Etbical Statement: The authors are accountable for all aspects of the work in ensuring that questions related to the accuracy or integrity of any part of the work are appropriately investigated and resolved.
Open Access Statement: This is an Open Access article distributed in accordance with the Creative Commons Attribution-NonCommercial-NoDerivs 4.0 International License (CC BY-NC-ND 4.0), which permits the noncommercial replication and distribution of the article with the strict proviso that no changes or edits are made and the original work is properly cited (including links to both the formal publication through the relevant DOI and the license). See: https://creativecommons.org/licenses/by-nc$\mathrm{nd} / 4.0 /$.

\section{References}

1. Heldal AT, Owe JF, Gilhus NE, et al. Seropositive myasthenia gravis: a nationwide epidemiologic study. Neurology 2009;73:150-1.

2. Andersen JB, Engeland A, Owe JF, et al. Myasthenia gravis requiring pyridostigmine treatment in a national population cohort. Eur J Neurol 2010;17:1445-50.

3. Carr AS, Cardwell CR, McCarron PO, et al. A systematic review of population based epidemiological studies in Myasthenia Gravis. BMC Neurol 2010;10:46.

4. Pakzad Z, Aziz T, Oger J. Increasing incidence of myasthenia gravis among elderly in British Columbia, Canada. Neurology 2011;76:1526-8.

5. Gilhus NE. Myasthenia and the neuromuscular junction. Curr Opin Neurol 2012;25:523-9.

6. Querol L, Illa I. Myasthenia gravis and the neuromuscular junction. Curr Opin Neurol 2013;26:459-65.

7. Evoli A, Alboini PE, Damato V, et al. 3,4-Diaminopyridine may improve myasthenia gravis with MuSK antibodies. Neurology 2016;86:1070-1.

8. Morsch M, Reddel SW, Ghazanfari N, et al. 
Pyridostigmine but not 3,4-diaminopyridine exacerbates $\mathrm{ACh}$ receptor loss and myasthenia induced in mice by muscle-specific kinase autoantibody. J Physiol 2013;591:2747-62.

9. Skjei KL, Lennon VA, Kuntz NL. Muscle specific kinase autoimmune myasthenia gravis in children: a case series. Neuromuscul Disord 2013;23:874-82.

10. Köhler W, Bucka C, Klingel R. A randomized and controlled study comparing immunoadsorption and plasma exchange in myasthenic crisis. J Clin Apher 2011;26:347-55.

11. Rønager J, Ravnborg M, Hermansen I, et al. Immunoglobulin treatment versus plasma exchange in patients with chronic moderate to severe myasthenia gravis. Artif Organs 2001;25:967-73.

12. Sanders DB, Burns TM, Cutter GR, et al. Does change in acetylcholine receptor antibody level correlate with clinical change in myasthenia gravis? Muscle Nerve 2014;49:483-6.

13. Andersen JB, Gilhus NE, Sanders DB. Factors affecting outcome in myasthenia gravis. Muscle Nerve 2016;54:1041-9.

14. Peeler CE, De Lott LB, Nagia L, et al. Clinical Utility of Acetylcholine Receptor Antibody Testing in Ocular Myasthenia Gravis. JAMA Neurol 2015;72:1170-4.

15. Wong SH, Petrie A, Plant GT. Ocular Myasthenia Gravis: Toward a Risk of Generalization Score and Sample Size Calculation for a Randomized Controlled Trial of Disease Modification. J Neuroophthalmol 2016;36:252-8.

16. Gomez AM, Van Den Broeck J, Vrolix K, et al. Antibody effector mechanisms in myasthenia gravis-pathogenesis at the neuromuscular junction. Autoimmunity 2010;43:353-70.

17. Verschuuren JJ, Huijbers MG, Plomp JJ, et al. Pathophysiology of myasthenia gravis with antibodies to the acetylcholine receptor, muscle-specific kinase and lowdensity lipoprotein receptor-related protein 4 . Autoimmun Rev 2013;12:918-23.

18. Benatar M. A systematic review of diagnostic studies in myasthenia gravis. Neuromuscul Disord 2006;16:459-67.

19. Grob D, Brunner N, Namba T, et al. Lifetime course of myasthenia gravis. Muscle Nerve 2008;37:141-9.

20. Lindstrom JM, Seybold ME, Lennon VA, et al. Antibody to acetylcholine receptor in myasthenia gravis. Prevalence, clinical correlates, and diagnostic value. Neurology 1976;26:1054-9.

21. Vincent A, Newsom-Davis J. Acetylcholine receptor antibody characteristics in myasthenia gravis. I. Patients with generalized myasthenia or disease restricted to ocular muscles. Clin Exp Immunol 1982;49:257-65.

22. Vincent A, Newsom-Davis J. Acetylcholine receptor antibody as a diagnostic test for myasthenia gravis: results in 153 validated cases and 2967 diagnostic assays. J Neurol Neurosurg Psychiatry 1985;48:1246-52.

23. Gao F, Zhao X, Zhang J, et al. Clinical features of patients with Myasthenia gravis from the Henan province, China. Muscle Nerve 2016;53:711-6.

24. Hong Y, Li HF, Skeie GO, et al. Autoantibody profile and clinical characteristics in a cohort of Chinese adult myasthenia gravis patients. J Neuroimmunol 2016;298:51-7.

25. Hong Y, Zisimopoulou P, Trakas N, et al. Multiple antibody detection in 'seronegative' myasthenia gravis patients. Eur J Neurol 2017;24:844-50.

26. Wang WW, Hao HJ, Gao F. Detection of multiple antibodies in myasthenia gravis and its clinical significance. Chin Med J (Engl) 2010;123:2555-8.

27. Drachman DB, Angus CW, Adams RN, et al. Myasthenic antibodies cross-link acetylcholine receptors to accelerate degradation. N Engl J Med 1978;298:1116-22.

28. Gomez CM, Richman DP. Anti-acetylcholine receptor antibodies directed against the alpha-bungarotoxin binding site induce a unique form of experimental myasthenia. Proc Natl Acad Sci U S A 1983;80:4089-93.

29. Kao I, Drachman DB. Myasthenic immunoglobulin accelerates acetylcholine receptor degradation. Science 1977;196:527-9.

30. Maselli RA, Richman DP, Wollmann RL. Inflammation at the neuromuscular junction in myasthenia gravis. Neurology 1991;41:1497-504.

31. Richman DP, Agius MA, Kirvan CA, et al. Antibody effector mechanisms in myasthenia gravis. The complement hypothesis. Ann N Y Acad Sci 1998;841:450-65.

32. Tzartos SJ, Lindstrom JM. Monoclonal antibodies used to probe acetylcholine receptor structure: localization of the main immunogenic region and detection of similarities between subunits. Proc Natl Acad Sci U S A 1980;77:755-9.

33. Kordas G, Lagoumintzis G, Sideris S, et al. Direct proof of the in vivo pathogenic role of the AChR autoantibodies from myasthenia gravis patients. PLoS One 2014;9:e108327.

34. Masuda T, Motomura M, Utsugisawa K, et al. Antibodies against the main immunogenic region of the acetylcholine receptor correlate with disease severity in myasthenia gravis. J Neurol Neurosurg Psychiatry 2012;83:935-40.

35. Oosterhuis HJ, Limburg PC, Hummel-Tappel E, et al. 
Anti-acetylcholine receptor antibodies in myasthenia gravis. Part 2. Clinical and serological follow-up of individual patients. J Neurol Sci 1983;58:371-85.

36. Heldal AT, Eide GE, Romi F, et al. Repeated acetylcholine receptor antibody-concentrations and association to clinical myasthenia gravis development. PLoS One 2014;9:e114060.

37. Barnett C, Katzberg H, Nabavi M, et al. The quantitative myasthenia gravis score: comparison with clinical, electrophysiological, and laboratory markers. J Clin Neuromuscul Dis 2012;13:201-5.

38. Sine SM. Functional properties of human skeletal muscle acetylcholine receptors expressed by the TE671 cell line. J Biol Chem 1988;263:18052-62.

39. Somnier FE. Anti-acetylcholine receptor (AChR) antibodies measurement in myasthenia gravis: the use of cell line TE671 as a source of AChR antigen. J Neuroimmunol 1994;51:63-8.

40. Beeson D, Amar M, Bermudez I, et al. Stable functional expression of the adult subtype of human muscle acetylcholine receptor following transfection of the human rhabdomyosarcoma cell line TE671 with cDNA encoding the epsilon subunit. Neurosci Lett 1996;207:57-60.

41. Beeson D, Jacobson L, Newsom-Davis J, et al. A transfected human muscle cell line expressing the adult subtype of the human muscle acetylcholine receptor for diagnostic assays in myasthenia gravis. Neurology 1996;47:1552-5.

42. Ohta K, Fujinami A, Saida T, et al. Frequency of antiAChR epsilon subunit-specific antibodies in MG. Autoimmunity 2003;36:151-4.

43. Furukawa S, Akazawa S, Furukawa Y, et al. A practical enzyme immunoassay for anti-acetylcholine receptor antibodies in myasthenia gravis. J Neuroimmunol 1984;6:397-409.

44. Hewer R, Matthews I, Chen S, et al. A sensitive nonisotopic assay for acetylcholine receptor autoantibodies. Clin Chim Acta 2006;364:159-66.

45. Jacob S, Viegas S, Leite MI, et al. Presence and pathogenic relevance of antibodies to clustered acetylcholine receptor in ocular and generalized myasthenia gravis. Arch Neurol 2012;69:994-1001.

46. Leite MI, Jacob S, Viegas S, et al. IgG1 antibodies to acetylcholine receptors in 'seronegative' myasthenia gravis. Brain 2008;131:1940-52.

47. Rodríguez Cruz PM, Al-Hajjar M, Huda S, et al. Clinical Features and Diagnostic Usefulness of Antibodies to Clustered Acetylcholine Receptors in the Diagnosis of Seronegative Myasthenia Gravis. JAMA Neurol 2015;72:642-9.

48. Yang L, Maxwell S, Leite MI, et al. Non-radioactive serological diagnosis of myasthenia gravis and clinical features of patients from Tianjin, China. J Neurol Sci 2011;301:71-6.

49. Hoch W, McConville J, Helms S, et al. Auto-antibodies to the receptor tyrosine kinase MuSK in patients with myasthenia gravis without acetylcholine receptor antibodies. Nat Med 2001;7:365-8.

50. Mantegazza R, Antozzi C. When myasthenia gravis is deemed refractory: clinical signposts and treatment strategies. Ther Adv Neurol Disord 2018;11:1756285617749134.

51. Matthews I, Chen S, Hewer R, et al. Musclespecific receptor tyrosine kinase autoantibodies-a new immunoprecipitation assay. Clin Chim Acta 2004;348:95-9.

52. Zisimopoulou P, Brenner T, Trakas N, et al. Serological diagnostics in myasthenia gravis based on novel assays and recently identified antigens. Autoimmun Rev 2013;12:924-30.

53. Gilhus NE. Myasthenia Gravis. N Engl J Med 2016;375:2570-81.

54. Leite MI, Waters P, Vincent A. Diagnostic use of autoantibodies in myasthenia gravis. Autoimmunity 2010;43:371-9.

55. Romi F, Aarli JA, Gilhus NE. Seronegative myasthenia gravis: disease severity and prognosis. Eur J Neurol 2005;12:413-8.

56. Klooster R, Plomp JJ, Huijbers MG, et al. Muscle-specific kinase myasthenia gravis IgG4 autoantibodies cause severe neuromuscular junction dysfunction in mice. Brain 2012;135:1081-101.

57. Huijbers MG, Zhang W, Klooster R, et al. MuSK IgG4 autoantibodies cause myasthenia gravis by inhibiting binding between MuSK and Lrp4. Proc Natl Acad Sci U S A 2013;110:20783-8.

58. Koneczny I, Cossins J, Waters P, et al. MuSK myasthenia gravis IgG4 disrupts the interaction of LRP4 with MuSK but both IgG4 and IgG1-3 can disperse preformed agrinindependent AChR clusters. PLoS One 2013;8:e80695.

59. Plomp JJ, Huijbers MG, van der Maarel SM, et al. Pathogenic IgG4 subclass autoantibodies in MuSK myasthenia gravis. Ann N Y Acad Sci 2012;1275:114-22.

60. Bartoccioni E, Scuderi F, Minicuci GM, et al. Anti-MuSK antibodies: correlation with myasthenia gravis severity. Neurology 2006;67:505-7. 
61. Guptill JT, Sanders DB, Evoli A. Anti-MuSK antibody myasthenia gravis: clinical findings and response to treatment in two large cohorts. Muscle Nerve 2011;44:36-40.

62. McConville J, Farrugia ME, Beeson D, et al. Detection and characterization of MuSK antibodies in seronegative myasthenia gravis. Ann Neurol 2004;55:580-4.

63. Trakas N, Zisimopoulou P, Tzartos SJ. Development of a highly sensitive diagnostic assay for muscle-specific tyrosine kinase (MuSK) autoantibodies in myasthenia gravis. J Neuroimmunol 2011;240-241:79-86.

64. Gilhus NE, Verschuuren JJ. Myasthenia gravis: subgroup classification and therapeutic strategies. Lancet Neurol 2015;14:1023-36.

65. Tsonis AI, Zisimopoulou P, Lazaridis K, et al. MuSK autoantibodies in myasthenia gravis detected by cell based assay--A multinational study. J Neuroimmunol 2015;284:10-7.

66. Chang T, Leite MI, Senanayake S, et al. Clinical and serological study of myasthenia gravis using both radioimmunoprecipitation and cell-based assays in a South Asian population. J Neurol Sci 2014;343:82-7.

67. Higuchi O, Hamuro J, Motomura M, et al. Autoantibodies to low-density lipoprotein receptor-related protein 4 in myasthenia gravis. Ann Neurol 2011;69:418-22.

68. Pevzner A, Schoser B, Peters K, et al. Anti-LRP4 autoantibodies in AChR- and MuSK-antibody-negative myasthenia gravis. J Neurol 2012;259:427-35.

69. Zhang B, Tzartos JS, Belimezi M, et al. Autoantibodies to lipoprotein-related protein 4 in patients with double-seronegative myasthenia gravis. Arch Neurol 2012;69:445-51.

70. Zisimopoulou P, Evangelakou P, Tzartos J, et al. A comprehensive analysis of the epidemiology and clinical characteristics of anti-LRP4 in myasthenia gravis. J Autoimmun 2014;52:139-45.

71. Li Y, Zhang Y, Cai G, et al. Anti-LRP4 autoantibodies in Chinese patients with myasthenia gravis. Muscle Nerve 2017;56:938-42.

72. Yan M, Xing GL, Xiong WC, et al. Agrin and LRP4 antibodies as new biomarkers of myasthenia gravis. Ann N Y Acad Sci 2018;1413:126-35.

73. Barik A, Lu Y, Sathyamurthy A, et al. LRP4 is critical for neuromuscular junction maintenance. J Neurosci 2014;34:13892-905.

74. Lu Y, Tian QB, Endo S, et al. A role for LRP4 in neuronal cell viability is related to apoE-binding. Brain Res 2007;1177:19-28.

75. Shen C, Lu Y, Zhang B, et al. Antibodies against low- density lipoprotein receptor-related protein 4 induce myasthenia gravis. J Clin Invest 2013;123:5190-202.

76. Bacchi S, Kramer P, Chalk C. Autoantibodies to LowDensity Lipoprotein Receptor-Related Protein 4 in Double Seronegative Myasthenia Gravis: A Systematic Review. Can J Neurol Sci 2018;45:62-7.

77. Skeie GO, Aarli JA, Gilhus NE. Titin and ryanodine receptor antibodies in myasthenia gravis. Acta Neurol Scand Suppl 2006;183:19-23.

78. Skeie GO, Mygland A, Treves S, et al. Ryanodine receptor antibodies in myasthenia gravis: epitope mapping and effect on calcium release in vitro. Muscle Nerve 2003;27:81-9.

79. Romi F, Skeie GO, Aarli JA, et al. Muscle autoantibodies in subgroups of myasthenia gravis patients. J Neurol 2000;247:369-75.

80. Stergiou C, Lazaridis K, Zouvelou V, et al. Titin antibodies in "seronegative" myasthenia gravis--A new role for an old antigen. J Neuroimmunol 2016;292:108-15.

81. Skeie GO, Apostolski S, Evoli A, et al. Guidelines for treatment of autoimmune neuromuscular transmission disorders. Eur J Neurol 2010;17:893-902.

82. Chen XJ, Qiao J, Xiao BG, et al. The significance of titin antibodies in myasthenia gravis--correlation with thymoma and severity of myasthenia gravis. J Neurol 2004;251:1006-11.

83. Huang K, Shojania K, Chapman K, et al. Concurrent inflammatory myopathy and myasthenia gravis with or without thymic pathology: A case series and literature review. Semin Arthritis Rheum 2019;48:745-51.

84. Suzuki S, Utsugisawa K, Yoshikawa H, et al. Autoimmune targets of heart and skeletal muscles in myasthenia gravis. Arch Neurol 2009;66:1334-8.

85. Romi F, Aarli JA, Gilhus NE. Myasthenia gravis patients with ryanodine receptor antibodies have distinctive clinical features. Eur J Neurol 2007;14:617-20.

86. Szczudlik P, Szyluk B, Lipowska M, et al. Antititin antibody in early- and late-onset myasthenia gravis. Acta Neurol Scand 2014;130:229-33.

87. Gasperi C, Melms A, Schoser B, et al. Anti-agrin autoantibodies in myasthenia gravis. Neurology 2014;82:1976-83.

88. Witzemann V, Chevessier F, Pacifici PG, et al. The neuromuscular junction: selective remodeling of synaptic regulators at the nerve/muscle interface. Mech Dev 2013;130:402-11.

89. Tyack PL, Calambokidis J, Friedlaender A, et al. Formal Comment on Schorr GS, Falcone EA, Moretti DJ, Andrews RD (2014) First Long-Term Behavioral Records 
from Cuvier's Beaked Whales (Ziphius cavirostris)

Reveal Record-Breaking Dives. PLoS ONE 9(3):

e92633. doi:10.1371/journal.pone.0092633. PLoS One 2015;10:e0142287.

90. Zoltowska Katarzyna M, Belaya K, Leite M, et al. Collagen Q--a potential target for autoantibodies in myasthenia gravis. J Neurol Sci 2015;348:241-4.

91. Romi F, Suzuki S, Suzuki N, et al. Anti-voltage-gated potassium channel Kv1.4 antibodies in myasthenia gravis. J

Cite this article as: Li Y, Peng Y, Yang H. Serological diagnosis of myasthenia gravis and its clinical significance. Ann Transl Med 2023;11(7):290. doi: 10.21037/atm-19-363
Neurol 2012;259:1312-6.

92. Suzuki S, Baba A, Kaida K, et al. Cardiac involvements in myasthenia gravis associated with anti-Kv1.4 antibodies. Eur J Neurol 2014;21:223-30.

93. Suzuki S, Satoh T, Yasuoka H, et al. Novel autoantibodies to a voltage-gated potassium channel $\mathrm{Kv} 1.4$ in a severe form of myasthenia gravis. J Neuroimmunol 2005;170:141-9. 